\title{
PRESENTACIÓN DE LA EDICIÓN
}

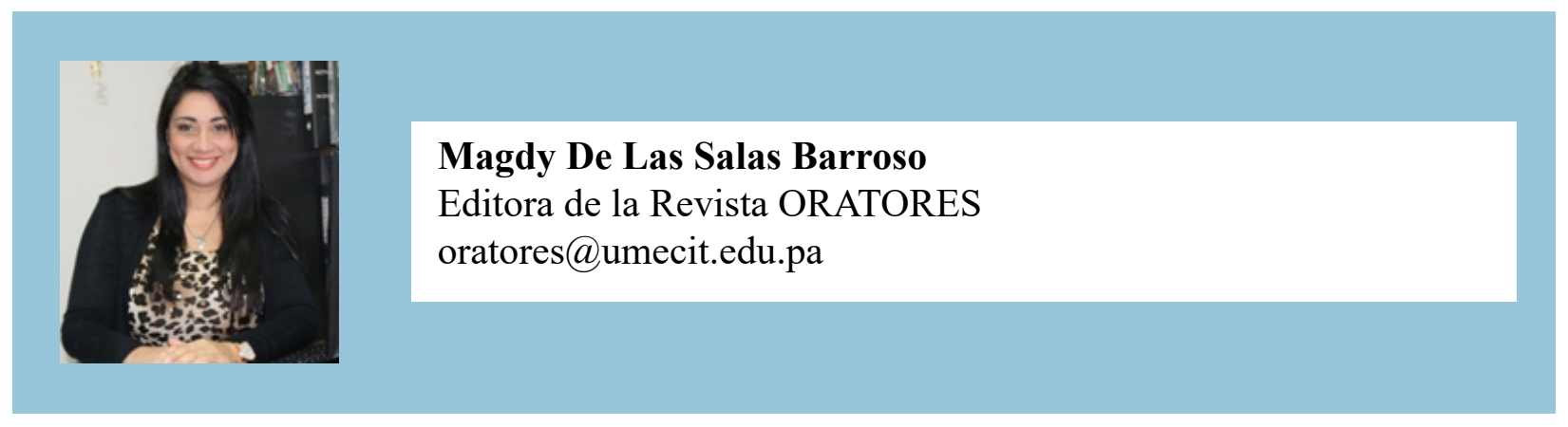

La Universidad Metropolitana de Educación, Ciencia y Tecnología (UMECIT), se complace en presentarles nuestra edición número 6, año 5 de la Revista ORATORES, correspondiente a Junio - Noviembre 2017, por primera vez en formato impreso y digital, lo cual evidencia el compromiso institucional para hacer uso de nuevos espacios que permitan incrementar la visibilidad de nuestras publicaciones y posicionarnos en el contexto académico nacional e internacional, haciendo uso de herramientas y plataformas tecnológicas para la difusión de los productos intelectuales de los autores, que sin duda, fortalecen la revista.

Un total de cinco (05) artículos de investigación y un (01) ensayo científico se presentan en esta edición, iniciando con el artículo de Ángel Santos Pérez González, estudiante de la Licenciatura en Gestión ambiental de la sede Chitré de UMECIT, Panamá, titulado "La reforestación del área de uso público y los efectos del Arco Seco de Azuero" donde plantea la importancia de la reforestación de estas áreas de uso público y un análisis sobre los costos para la adquisición, plantación y mantenimiento de los árboles que se puedan sembrar en los espacios de uso público y los beneficios que puede brindar al medio ambiente

Ingrid Benavides Hernández, Louisa Williams y Gissell Carrasquilla, Panamá, en su ensayo titulado "El proceso de duelo dentro del núcleo familiar por la muerte de un infante", destacan desde un análisis social, todo lo que sucede dentro del núcleo familiar cuando se pierde la vida de un Infante y describe las etapas de: negación, ira, negociación, depresión y aceptación manejadas dentro de una familia que lucha contra el dolor de la pérdida de un ser querido.

José Rogelio Fung Corro, docente e investigador de la sede Santiago de UMECIT, Panamá, en su artículo titulado “Cultura digital en Benemérito Cuerpo de Bomberos de la República 
de Panamá", plantea la migración de tecnología análoga a tecnología digital resaltando que la Cultura Digital es de suma importancia para la sensibilización y concientización de los usuarios como principales protagonistas, para contrarrestar la tecnofobia y erradicar el analfabetismo tecnológico, como unos de los problemas que aquejan esta era digital.

Seguidamente, Marhilde Sánchez, Marisela Árraga y Ligia Pirela, docentes e investigadoras de La Universidad del Zulia, Venezuela, en su artículo titulado "Inteligencia emocional. Efectos sobre el rendimiento académico en estudiantes de educación", describen los efectos del desarrollo de un programa de intervención psicológica basado en la inteligencia emocional en el rendimiento académico de estudiantes de la Escuela de Educación, mención química. La administración de dicho programa permitió constatar la importancia de la Inteligencia emocional en el desarrollo integral de los estudiantes, pues contribuye a minimizar las posibilidades de deserción, tomando en cuenta la vulnerabilidad y otras situaciones de riesgo en los estudiantes.

Rosalba Rivera Dueñas, Colombia aborda en su artículo "Evaluación del aprendizaje: La razón para la formación integral del policía", el procedimiento de evaluación del aprendizaje en una escuela de formación de la Policía Nacional de Colombia, teniendo en cuenta que la formación integral en la educación de los seres humanos y su validación se basa en un principio denominado "evaluación del aprendizaje". Se determinaron las concepciones y prácticas evaluativas predominantes en la acción pedagógica de los docentes de la escuela, propendiendo por la actualización y mejoramiento de la práctica evaluativa acorde a los nuevos desafíos del sistema educativo.

Para finalizar esta edición, Celia Llanusa Ruiz, Panamá Johana Gutiérrez Zehr, Colombia y Luis Sotillo Bent, Panamá; nos presentan entre las conclusiones de su artículo "Evaluación del conocimiento sobre los factores de riesgo asociados a defectos congénitos en mujeres en edad reproductiva en Panamá", que existe un deficiente conocimiento según la percepción por parte de las mujeres entrevistadas, de los factores involucrados en el origen de las anomalías congénitas, muchos de ellos controlables y cuya exposición puede evitarse en embarazo. Esto lleva a reflexionar sobre la necesidad de desarrollar estrategias preventivas.

Amigos lectores, disfruten esta edición y esperamos que sea de provecho académico para todos. 